\title{
Study on Loan Pricing of Small and Medium Sized Enterprises based on RAROC Model
}

\author{
Qian Chen $^{1}$ Mu Zhang ${ }^{2,3}$ \\ ${ }^{1}$ Guizhou Institute for Urban Economics and Development, Guizhou University of \\ Finance and Economics, Guiyang Guizhou 550025, China \\ ${ }^{2}$ Guizhou Institution for Technology Innovation \& Entrepreneurship Investment, Guizhou \\ University of Finance and Economics, Guiyang Guizhou 550025, China \\ ${ }^{3}$ School of Finance, Guizhou University of Finance and Economics, Guiyang Guizhou \\ 550025, China

\begin{abstract}
Commercial bank is the product of economic development and occupies a very important position in the economic system, and loan pricing is one of the core management problems of commercial banks.Based on the loan pricing method of RAROC model, this paper calculates the expected loss, the economic capital and other related parameters of small and medium-sized enterprises, and obtains the loan pricing which covers the sample of small and medium-sized enterprises risk.This paper argues that the loan pricing method based on the RAROC model can measure the loan risk and give the appropriate price compensation, which will help to improve the risk control ability and the efficiency of the use of funds in China's banking industry.
\end{abstract}

\section{Keywords}

RAROC; Loan pricing; Small and medium-sized enterprises; Economic capitale; Expected loss

\section{基于 RAROC 模型的中小企业贷款定价 研究}

\author{
陈倩 1 张目 ${ }^{2,3}$ \\ 1 贵州财经大学贵州城镇经济与发展研究院，贵阳，贵州, 550025, 中国 \\ 2 贵州财经大学贵州科技创新创业投资研究院，贵阳，贵州, 550025, 中国 \\ 3 贵州财经大学金融学院，贵阳，贵州, 550025, 中国
}

摘要：商业银行是经济发展的产物, 在经济体系中占有十分重要的地位, 而贷款定价是商业 银行的核心管理问题之一。本文基于 RAROC 模型的贷款定价方法，对样本中小企业的预期 损失、经济资本等相关参数进行了计算，得出全面涵盖样本中小企业风险的贷款定价。本文 
认为基于 RAROC 模型的贷款定价方法可以衡量贷款风险并给出适当的价格补偿, 这有助于 我国银行业风险控制能力和资金使用效率的提高

关键词：RAROC；贷款定价；中小企业；经济资本；预期损失

\section{1. 引言}

商业银行是经济发展的产物，在 经济体系中占有十分重要的地位, 而 贷款定价是商业银行的核心管理问题 之一。在国家大力提倡调整信贷结 构、加大对中小企业扶持力度的政策 下，商业银行的经营策略也在向中小 企业倾斜, 但在实际运行、操作过程 中依旧存在许多问题, 其中, 中小企 业的贷款定价问题显得尤为突出。

中小企业方面, 王静、周宗放和 霍学喜（2010）[1]指出由于中小企业信 息不透明且常常不能提供充分的担保 或抵押，正规金融部门为了降低贷款 风险, 往往实施信贷配给。蒙震、胡 怀邦（2014）[2]结合我国中小企业特点 以及商业银行风险管理的经验, 提出 了一个较为全面涵盖我国中小企业信 用风险评估内容的度量模型, 并基于 该模型探讨我国商业银行的贷款定价 影响机制。黄春燕、张目、李岩和席 春红（2014） [3]在借鉴现有企业信用风 险评价技术和方法的基础上，针对科 技型中小企业一直承受着的资金短缺 和融资困难困扰问题，建立符合科技 型中小企业特征的信用风险评价指标 体系。钱茜、周宗放（2014） [4]针对供 应链背景下的中小企业的信用风险评 价问题展开讨论，在分析影响供应链 中的中小企业信用风险的主要因素的 基础上, 构建了相应的信用风险评价 指标体系。

目前西方商业银行已建立起了较 为成熟的贷款定价方法, 其中 RAROC 方法作为最有效的贷款定价方法已被 广泛采用, 理论方法与实证分析也在 随之发展与完善。
周朝阳、王皓白（2012）[5]基于 RAROC 贷款定价模型实证得出全面涵 盖样本企业风险的贷款定价, 并与银 行的实际定价进行比较分析。殷颖 (2012) [6]通过分析国内商业银行现 状, 认为 RAROC 定价方法考虑客户 共享程度、资本占用成本比重、风险 补偿等因素。高佳妲（2013）[7]运用 RAROC 方法, 对我国商业银行中小企 业贷款定价相关问题进行了分析，发 现随着信用评级的逐渐降低, RAROC 值越来越高于实际利率。潘凌遥、蒋 达（2014） ${ }^{[8]}$ 采用结构化模型对企业预 期违约概率进行精细测算, 并将所获 得的企业违约概率整合到 RAROC 贷 款定价模型中，提高企业贷款定价的 合理性。黄纪宪、顾柳柳（2014） [9]使 用基于客户关系的 RAROC 贷款定价 模型对贷款样本进行实证分析, 认为 RAROC 定价法有助于贷款议价能力与 营销能力的提升。孟彩云 (2014) [10] 基于 RAROC 的贷款定价模型, 选取 了 2012 年向建设银行借款的 11 家上 市公司作为样本, 通过实证研究得出 银行现行定价总体上略高于贷款风险 定价。

\section{RAROC 贷款定价模型}

\subsection{RAROC 模型基本概述}

RAROC 模型就是把商业银行经营 的安全和盈利性当做目标，对于资金 成本经营费用、预期损失以及风险损 失等因素进行综合考量的贷款定价模 型。

RAROC 模型的中心思想是在贷款 定价过程中引入风险函数, 将预期损 
失以及非预期损失同时考虑在内, 其 中前者代表当期成本，后者代表的是 经济资本, 采用风险调整后的收益指 标。RAROC 模型不仅能够促进其资本 结构的更加合理，同时也能够使商业 银行的风险和收益更加匹配。

\subsection{RAROC 模型公式推导}

RAROC 贷款定价模型中，经济资 本起着基础性的作用, 首先对违约事 件的概率进行计算, 得到相应的可能 性, 在对其进行相应的收益匹配, 进 而得到相应的价格。分子为经风险调 整的收益而分母则表示所占用的经济 资本。即:

$$
\begin{aligned}
& R A R O C=\frac{\text { 净收益 }- \text { 预期损失 }}{\text { 经济资本 }} \\
& =\frac{\text { 风险调整期望收益 }}{\text { 经济资本 }} \\
& =\frac{r L-i D-E L-O c L}{E C}
\end{aligned}
$$

其中, 贷款额度为 $\mathrm{L}$, 贷款利率为 $\mathrm{r}$, 为发放这笔贷款所占用的存款为 $\mathrm{D}$, 资金成本率为 $\mathrm{i}$, 经营成本率为 oc, 预 期损失率为 $\mathrm{e}$ ，该笔贷款所占用的经济 资本是 $\mathrm{EC}$ 。

因此，贷款利率可以表示为:

$$
r=(R A R O C-i) \times \frac{E C}{L}+\mathrm{i}+o c+e
$$

\section{3. 基于 RAROC 模型的贷款定价实 证研究}

\section{1. 样本选取}

本文选取 2015 年初向中国银行贷 款的 5 家上市中小企业作为研究对 象, 分别为: 同洲电子、劲嘉股份、 皇氏集团、海普瑞、科林环保。本文 所有数据均来自中国银行年报、5 家中
小企业年报、国泰安贷款数据库、同 花顺股票，具体数据如表 1 所示。

表 1 ：样本企业贷款额、期限和担保形式

\begin{tabular}{|c|c|c|c|}
\hline 样本企业 & 贷款额 & 期限 & 担保形式 \\
\hline 同洲电子 & 20000 万元 & 1 年 & 担保 \\
\hline 劲嘉股份 & 30000 万元 & 1 年 & 信用 \\
\hline 皇氏集团 & 8000 万元 & 1 年 & 信用 \\
\hline 海普瑞 & 20000 万元 & 1 年 & 信用 \\
\hline 科林环保 & 20000 万元 & 1 年 & 信用 \\
\hline
\end{tabular}

\section{2. 主要参数值计算}

根据 RAROC 模型公式推导可以 看出, 要得到贷款利率就要对经营成 本率（oc）、资金成本率（i）、 RAROC、经济资本（EC）、预期损失 (EL) 及贷款额（L）等参数进行精确 的选取和计量。

\subsection{1 预期损失的计量}

(1) 样本企业的违约概率 (EDF)

本文选用了 $\mathrm{KMV}$ 模型来计算样本 企业的违约距离和违约概率, 以 wind 资讯金融终端中 5 个样本企业 2015 年 的股票每日收盘价和股份数为研究对 象, 计算得出 5 家样本企业股权价值 $\mathrm{VE}$ 和股权波动率 $\sigma \mathrm{E}$, 违约发生最频繁 的临界点 DP 等于流动负债加 50\%的长 期负债，算得的数据见表 2 。

表 2 : 样本企业的违约损失率

\begin{tabular}{|c|c|c|c|}
\hline & 股权价值 & 波动率 & 长期负债 \\
\hline 同洲电子 & 8547752476 & 0.501 & 12783934.29 \\
\hline 劲嘉股份 & 19955433509 & 0.817 & 25581131.31 \\
\hline 皇氏集团 & 13011037083 & 1.318 & 296902987.3 \\
\hline 海普瑞 & 28303074000 & 0.455 & 2454958663 \\
\hline 科林环保 & 3468569546 & 0.676 & 61737426.82 \\
\hline & 短期负债 & 违约发生的临界点短 \\
\hline 同洲电子 & 1515607900 & \multicolumn{2}{|c|}{1521999867} \\
\hline 劲嘉股份 & 967571070.8 & \multicolumn{2}{|c|}{980361636.4} \\
\hline 皇氏集团 & 1377164845 & \multicolumn{2}{|c|}{1525616338} \\
\hline 海普瑞 & 920480293.7 & \multicolumn{2}{|c|}{2147959625} \\
\hline 科林环保 & 217710551.8 & \multicolumn{2}{|c}{248579265.2} \\
\hline
\end{tabular}


本文使用 MATLAB 统计软件对表 2 数据进行计算分析。运用 KMV 模型 计算出样本企业的股权价值、股权价 值波动率、违约点及违约距离、企业 资产的市场价值及其波动率以及预期 违约概率, 具体见表 3 。

表 3 : 样本企业的资产市价、资产波动 率、违约距离和违约概率

\begin{tabular}{|c|c|c|}
\hline & 资产市值 & 资产波动率 \\
\hline 同洲电子 & 10037079449 万元 & 0.4264 \\
\hline 劲嘉股份 & 20914721976 万元 & 0.7794 \\
\hline 皇氏集团 & 10947390314 万元 & 0.3108 \\
\hline 海普瑞 & 30404924988 万元 & 0.4596 \\
\hline 科林环保 & 3711811778 万元 & 0.6316 \\
\hline & 违约距离 & 违约概率 \\
\hline 同洲电子 & 1.9897 & 0.0023 \\
\hline 劲嘉股份 & 1.2229 & 0.1107 \\
\hline 皇氏集团 & 2.7696 & 0.0028 \\
\hline 海普瑞 & 2.0222 & 0.02158 \\
\hline 科林环保 & 1.4773 & 0.0070 \\
\hline
\end{tabular}

\section{(2) 风险暴露（EAD）}

初级法的风险敞口根据监管当局 制定的标准计算：对于表内项目，其 $\mathrm{EAD}$ 为名义贷款额; 对表外项目, $\mathrm{EAD}$ 为账面金额乘以信用转换因子。

由于本文中的样本企业的贷款用 途不详，因此谨慎起见，假设所有贷 款都为表内项目，即各企业的风险暴 露都为他们的名义贷款额, 各样本企 业贷款额见表 1 。

（3）违约损失率（LGD）。

由于本文样本企业的担保方式和 抵押、质押物品价值等信息不全, 因 此保守起见取 $\mathrm{LGD}=50 \%$, 以保障商 业银行经营的安全。

表 4 : 同业经验金融机构的违约损失率

\begin{tabular}{|c|c|}
\hline 担保情况 & 经验违约损失率 \\
\hline 信用 & $45 \%$ \\
\hline 抵押、质押 & $50 \%$ \\
\hline 保证 & $55 \%$ \\
\hline
\end{tabular}

\subsection{2 经济资本和资金成本率的计量}

\section{(1) 经济资本 (EC)}

经济资本是根据内部风险度量模 型计算得到的银行在未来一定时期所 面临的非预期损失, 在数量上, 经济 资本就等于非预期损失。

根据新资本协议规定, 在置信度 为 $99.9 \%$ 的情况下，分配给债务人的经 济资本 $\mathrm{EC}$ 表示为:

$$
E C=\alpha \times E A D
$$

其中, $\alpha$ 表示资本要求, 具体计算 公式如下:

$$
\begin{aligned}
& \alpha=\left\{L G D \times \Phi\left[\frac{\Phi^{-1}(E D F)}{\sqrt{1-R}}+\Phi^{-1}(0.999) \times \sqrt{\frac{R}{1-R}}\right]-E D F \times L G D\right\} \\
& \times \frac{1+(M-2.5) \times b}{1-1.5 b} \\
& \quad \mathrm{R} \text { 表示相关系数, 计算公式如 }
\end{aligned}
$$
下:

$$
R(E D F)=0.12 \times \frac{1-e^{-50 \times E D F}}{1-e^{-50}}+0.24 \times\left(1-\frac{1-e^{-50 \times E D F}}{1-e^{-50}}\right)
$$

b 表示期限调整, 计算公式如下:

$$
b=[0.11852-0.05478 \times \ln (E D F)]^{2}
$$

将数据带入以上公式, 计算得到 样本企业每笔贷款应配置的经济资 本, 如表 5。

表 5 : 经济资本配置结果

\begin{tabular}{|c|c|c|c|}
\hline & 风险暴露 & 期限调整 & 相关系数 \\
\hline 同洲电子 & 20000 万元 & 0.203 & 0.040 \\
\hline 劲嘉股份 & 30000 万元 & 0.057 & 0.359 \\
\hline 皇氏集团 & 8000 万元 & 0.194 & 0.0471 \\
\hline 海普瑞 & 20000 万元 & 0.108 & 0.238 \\
\hline 科林环保 & 20000 万元 & 0.152 & 0.106 \\
\hline & 资本要求 & 经济资本 \\
\hline 同洲电子 & 0.191 & 3816.96 万元 \\
\hline 劲嘉股份 & 0.0536 & 1609.24 万元 \\
\hline 皇氏集团 & 0.190 & 1520.29 万元 \\
\hline 海普瑞 & 0.164 & \multicolumn{2}{|c|}{3282.85 万元 } \\
\hline 科林环保 & 0.1847 & \multicolumn{2}{|c|}{3679.68 万元 } \\
\hline
\end{tabular}


（5）资金成本率（i）

本文中的资金成本取样本企业的 贷款额在 $\mathrm{T}$ 年中的成本, 利率 $\mathrm{r}$ 通过 加权计算中国人民银行一年期存款利 率, 得出 2015 年的无风险利率 $\mathrm{rf}$ 为 $2.17 \%, \mathrm{~T}$ 为贷款期限。资金成本率为 资金成本与负债额 $\mathrm{D}$ 之比, 由于 $\mathrm{D}=\mathrm{L}-\mathrm{EC}$ ，所以资金成本率为资金成本 与 (L-EC) 的比值。资金成本率计算 结果见表 6 。

表 6 ：资金成本率

\begin{tabular}{|c|c|c|c|}
\hline & 贷款额 & 年限 & 存款利率 \\
\hline 同洲电子 & 20000 万元 & 1 年 & $2.17 \%$ \\
\hline 劲嘉股份 & 30000 万元 & 1 年 & $2.17 \%$ \\
\hline 皇氏集团 & 8000 万元 & 1 年 & $2.17 \%$ \\
\hline 海普瑞 & 20000 万元 & 1 年 & $2.17 \%$ \\
\hline 科林环保 & 20000 万元 & 1 年 & $2.17 \%$ \\
\hline & 资金成本 & $\begin{array}{c}\text { 经济 } \\
\text { 资本 }\end{array}$ & 资金成本率 \\
\hline 同洲电子 & $\begin{array}{c}434 \\
\text { 万元 }\end{array}$ & $\begin{array}{c}3816.96 \\
\text { 万元 }\end{array}$ & $2.682 \%$ \\
\hline 劲嘉股份 & $\begin{array}{c}651 \\
\text { 万元 }\end{array}$ & $\begin{array}{c}1609.24 \\
\text { 万元 }\end{array}$ & $2.293 \%$ \\
\hline 皇氏集团 & $\begin{array}{c}173.6 \\
\text { 万元 }\end{array}$ & $\begin{array}{c}1520.29 \\
\text { 万元 }\end{array}$ & $2.679 \%$ \\
\hline & $\begin{array}{c}434 \\
\text { 万元 }\end{array}$ & $\begin{array}{c}3282.85 \\
\text { 万元 }\end{array}$ & $2.596 \%$ \\
\hline 海普瑞 & 万元 & $\begin{array}{c}3679.67 \\
\text { 万元 }\end{array}$ & $2.659 \%$ \\
\hline 科林环保 & $\begin{array}{c}434 \\
\text { 万元 }\end{array}$ \\
\hline
\end{tabular}

\subsection{3 经营成本率和 RAROC 的计量}

\section{(1) 经营成本率 (oc)}

经营成本是指商业银行在对企业 发放贷款的过程中发生的相关费用, 是商业银行非资金性经营成本。计算 公式如下:

贷款的经营成本率 $=(1$-手续费及 佣金净收入对营业收入比率） $\times$ 业务及 管理费/发放贷款和垫款总额

由中国银行年报可知, 该银行手 续费及佣金净收入为 790.21 亿元, 营 业收入为 4040 亿元，业务及管理费为 1169.72 亿元, 客户贷款和垫款总额为
91358.60 亿元, 可计算出银行贷款的 经营成本率 oc 为 $1.02 \%$ 。

(2) 风险调整后的资本收益率

\section{(RAROC)}

对商业银行而言，风险调整后的 资本收益率 RAROC 的确定与股东账 面资本回报要求相联系, 也取决于商 业银行的风险偏好, 国际上通常以税 后 $15 \%$ 为标准。本文按照国际通用惯 例, 取 RAROC $=15 \%$ 。

\section{3. 基于 RAROC 的贷款定价}

基于巴塞尔新资本协议框架构建 的 RAROC 贷款定价模型，本文对贷 款额经营成本、资金成本、风险成本 和经济资本等关键指标进行了测算, 并将以上指标带入到 RAROC 贷款定 价模型中, 可计算出样本企业每笔贷 款的风险定价, 结果如表 7 所示。

\begin{tabular}{|c|c|c|c|}
\multicolumn{2}{c|}{ 表 7 : 基于 RAROC 的贷款定价 } \\
\hline & 贷款额 & 资金成本率 & 预期损失率 \\
\hline 同洲电子 & 20000 万元 & $2.6819 \%$ & $2.331 \%$ \\
\hline 劲嘉股份 & 30000 万元 & $2.2930 \%$ & $11.068 \%$ \\
\hline 皇氏集团 & 8000 万元 & $2.6791 \%$ & $0.281 \%$ \\
\hline 海普瑞 & 20000 万元 & $2.5961 \%$ & $2.158 \%$ \\
\hline 科林环保 & 20000 万元 & $2.6593 \%$ & $6.980 \%$ \\
\hline & 经营成本率 & 经济资本 & 预测利率 \\
\hline 同洲电子 & $1.02 \%$ & 3816.96 万 & $8.38 \%$ \\
\hline 劲嘉股份 & $1.02 \%$ & 1609.24 万 & $15.06 \%$ \\
\hline 皇氏集团 & $1.02 \%$ & 1520.29 万 & $6.32 \%$ \\
\hline 海普瑞 & $1.02 \%$ & 3282.85 万 & $7.81 \%$ \\
\hline 科林环保 & $1.02 \%$ & 3679.67 万 & $12.93 \%$ \\
\hline
\end{tabular}

由表 7 所得数据可以看出, 基于 RAROC 模型计算得出的 5 个样本中小 企业的贷款利率最低为 $6.32 \%$, 最高为 $15.06 \%$ ， RAROC 贷款定价模型更加适 合的测算出贷款所面临的风险, 进而 得到更加有效的定价结果，从而保证 了商业银行贷款业务的收益性和安全 性。 


\section{4. 结论}

基于 RAROC 模型的贷款定价方 法能够较为准确地衡量中小企业贷款 风险并给出合理的贷款定价，提高银 行贷款的质量和效率; 同时可以衡量 贷款风险并给出适当的价格补偿, 这 有助于我国银行业风险控制能力和资 金使用效率的提高。

本文基于 RAROC 模型得出的定 价结果与银行实际定价具有差异，一 方面是由于目前中国银行只是在央行 规定的基准利率下浮动定价; 另一方 面是由于 RAROC 模型计算出的价格 没有反应出银企关系、关系贷款、行 业政策投放等因素造成的贷款价格优 惠, 因此是贷款的保守价格。另外由 于缺乏贷款数据积累和我国商业银行 风险管理水平的限制，本文的模型中 的重要参数如违约损失率、 RAROC 是 参考了巴塞尔新资本协议和国际银行 业的惯例，在一定程度上的保守定价 还有可能造成贷款价格的高估。

\section{参考文献}

[1] 王静, 周宗放, 霍学喜, 信贷配给 突变分析，中国灾害防御协会风险分 析专业委员会年会, 2010.

[2] 蒙震, 胡怀邦, 基于信用风险评估 的商业银行中小企业贷款定价影响 机制研究, 国际商务: 对外经济贸 易大学学报，5: 43-52，2014.

[3] 黄春燕, 张目, 李岩, 基于谱聚类 的科技型中小企业信用风险评价研 究，中国灾害防御协会风险分析专业 委员会年会, 2014.

[4] 钱茜, 周宗放, 基于供应链背景下 中小企业信用风险评价研究, 中国灾 害防御协会风险分析专业委员会年 会, 2014.

[5] 周朝阳, 王皓白, 基于 RAROC 模 型的商业银行贷款定价实证研究, 统计与决策, 21: 166-169, 2012.
６］殷颖，巴塞尔资本协议 III 对商业 银行贷款定价的影响研究, 复旦大 学，2012.

[7] 高佳姮, 基于 RAROC 的小企业贷 款定价研究，浙江大学，2013.

[8] 潘凌遥, 蒋达, 基于企业贷款角度 的 RAROC 贷款定价模型，系统工 程，3: 49-54， 2014.

[9] 黄纪宪, 顾柳柳, 贷款 RAROC 模 型定价与银行定价比较研究, 金 融论坛，5: 46-51，2014.

[10]孟彩云, 利率市场化下我国商业银 行贷款定价能力探讨- - 基于 RAROC 模型的贷款定价实证研 究, 西南金融, 2014. 